\title{
Bifidobacterium breve
}

National Cancer Institute

\section{Source}

National Cancer Institute. Bifidobacterium breve. NCI Thesaurus. Code C122248.

A bacterial species in the family Bifidobacteriaceae. B. breve ferments alpha-I-fucose but does not ferment D-blucuronate, arabinog alactan, xylan, porcine gastric mucin, or gums. This bacteria is a normal part of the gut flora and is frequently used as a probiotic. 